\title{
Core principles for infection prevention in hemodialysis centers during the COVID-19 pandemic
}

\author{
Gang Chen $\mathrm{MD}^{1}$, Yangzhong Zhou MD², Lei Zhang $\mathrm{MD}^{1}$, Ying Wang $\mathrm{MD}^{1}$, Rong-rong Hu MD${ }^{1}$, Xue Zhao MD ${ }^{1}$, Dan Song ${ }^{1}$, \\ Jing-hua Xia ${ }^{1}$, Yan Qin MD¹, Li-meng Chen MD ${ }^{1}$ and Xue-mei Li MD ${ }^{1}$ \\ ${ }^{1}$ Nephrology Department, Peking Union Medical College Hospital, Peking Union Medical College, Chinese Academy of Medical Sciences, Peking, China and \\ ${ }^{2}$ Internal Medicine, Peking Union Medical College Hospital, Peking Union Medical College, Chinese Academy of Medical Sciences, Peking, China
}

To the Editor-The COVID-19 outbreak began at the end of December 2019, and >600,000 confirmed cases had been reported worldwide by the end of March 2020. The World Health Organization declared a global pandemic. ${ }^{1}$ Nosocomial transmission was severe in some locations, and the burden to the health system was extreme. ${ }^{2}$ Hemodialysis centers, which generally serve high volumes of highly mobile dialysis patients, have an exceptionally high risk of exposure during this outbreak period. In a general tertiary-care hospital, dialysis centers routinely accept patients from outpatient clinics and emergency rooms, further adding to the difficulty of preventing nosocomial infection. ${ }^{3}$ Dialysis patients, commonly regarded as immune compromised, are likely to develop severe illness as a result of close contact in a medical unit.

Droplet spread and close contact are the main routes of COVID-19 transmission. ${ }^{4}$ Thus, the hemodialysis center in our hospital implemented multiple strategies for infection prevention, including area management and integrated symptom monitoring, in the context of this pandemic.

Based on various levels of exposure to the mobile population, our hospital environments were classified as low-risk, mediumrisk, high-risk, and extremely high-risk, and the dialysis center belongs to the high-risk category. We avoid moving across the area by designing a specific walking route for our patients entering the hemodialysis center. Medical staff wears personal protective equipment (PPE) when inter-area contact is inevitable. For example, N95 masks and protective glasses are required when entering the fever clinic. We advise the use of hand sanitizer whenever staff return to the hemodialysis center. In the dialysis center, a 1-way route is followed by our patients, and mask-wearing and hand sanitizing by the patients are ensured. During the dialysis session, we provide necessary education on maintaining social distancing and self-protection. Between the 2 dialysis shifts, we strictly leave at least 30 minutes for environmental and air disinfection, and we utilize a chlorine-containing disinfectant to clean our dialysis facilities. $^{6-8}$

We monitor and respond to our regular patients' symptoms in an integrated way. Between the dialysis sessions, we strictly record the body temperatures and any suspicious respiratory symptoms of our patients. For patients referred from other departments in the hospital, we collect records of their contact history, temperature, and potential warning symptoms before admission. Based on this information, all of our patients are classified into 3 categories (Table 1). A negative SARS-CoV-2 swab test is needed for patients

Author for correspondence: Xuemei Li MD, E-mail: Lixmpumch@126.com

Cite this article: Chen G, et al. (2020). Core principles for infection prevention in hemodialysis centers during the COVID-19 pandemic. Infection Control \& Hospital Epidemiology, 41: 865-866, https://doi.org/10.1017/ice.2020.109
Table 1. High-Risk and Suspicious Patient Identification and Classification Management

\begin{tabular}{lll}
\hline Category & \multicolumn{1}{c}{ Definition } & \multicolumn{1}{c}{ Management } \\
\hline $\begin{array}{l}\text { A: Temperature } \\
\text { warning }\end{array}$ & $\begin{array}{l}\text { Temperature } 37.0^{3} 3.2^{\circ} \mathrm{C} \\
\text { in the past } 14 \mathrm{~d} \text {, without } \\
\text { other symptoms }\end{array}$ & Close observation \\
\hline $\begin{array}{l}\text { B: Symptom } \\
\text { warning }\end{array}$ & $\begin{array}{l}\text { Suspicious symptoms } \\
\text { (ie, sore throat, cough, } \\
\text { and diarrhea, etc) in the } \\
\text { past } 14 \mathrm{~d} \text {; but the } \\
\text { temperature within the } \\
\text { normal range }\end{array}$ & $\begin{array}{l}\text { Separate dialysis and } \\
\text { close observation }\end{array}$ \\
& $\begin{array}{l}\text { Temperature }>37.3^{\circ} \mathrm{C} \\
\text { within } 14 \mathrm{~d} \text {, together with } \\
\text { suspicious history, or } \\
\text { respiratory symptoms, } \\
\text { or chest imaging } \\
\text { abnormalities }\end{array}$ & $\begin{array}{l}\text { Screen SARS-CoV-2 } \\
\text { swab; send positive } \\
\text { patients to the } \\
\text { specific hospitals; } \\
\text { arrange negative } \\
\text { patients for separate } \\
\text { dialysis and close } \\
\text { observation }\end{array}$ \\
\hline
\end{tabular}

in category $\mathrm{C}$ before their dialysis session can be scheduled. In emergency cases, we perform continuous renal replacement therapy (CRRT) in a separate place, preferably in a negative-pressure ward, before completely ruling out COVID-19 for these patients. ${ }^{5,6}$ Notably, patients with a positive swab test are sent to designated hospitals for further treatment.

Medical staff are strictly required to maintain hand hygiene and to wear a mask at work. N95 masks and protective goggles are used when operating CRRT for patients in category C. The equipment used is disinfected between patients, and medical waste is packed and labeled separately to avoid potential contamination. ${ }^{7}$ The waste liquid generated during CRRT is discharged according to the requirements of the medical wastewater discharge standards. ${ }^{8}$

In addition to the strategies summarized above, we promote work-life balance for staff and encourage patients to take the initiative to participate. Our hemodialysis center has strived to achieve zero infection during the ongoing COVID-19 outbreak.

Acknowledgments. The work is made possible through an ISN Sister Renal Center Cooperation.

Financial support. No financial support was provided relevant to this article.

Conflicts of interest. All authors report no conflicts of interest relevant to this article. 


\section{References}

1. Mahase E. Covid-19: WHO declares pandemic because of "alarming levels" of spread, severity, and inaction. BMJ 2020;368:m1036.

2. Wang D, Hu B, Hu C, et al. Clinical characteristics of 138 hospitalized patients with 2019 novel coronavirus-infected pneumonia in Wuhan, China. JAMA 2020. doi: 10.1001/jama.2020.1585.

3. Karkar A, Bouhaha BM, Dammang ML. Infection control in hemodialysis units: a quick access to essential elements. Saudi J Kidney Dis Transpl 2014;25:496-519. 4. Novel coronavirus pneumonia diagnosis and treatment plan (provisional 7th edition) National Health Commission of the People's Republic of China. https://www.chinalawtranslate.com/en/coronavirus-treatment-plan-7/. Published 2020. Accessed April 6, 2020.
5. National Center for Medical Quality Control of Kidney Diseases: Expert advice in hemodialysis room (center) to prevent and control the outbreak of novel coronavirus pneumonia. http://www.cnrds.net/Static/OfficialDocumentDown.html.

6. Expert team of Chinese Medical Association Nephrology Branch. Recommendations for prevention and control of novel coronavirus infection in blood purification center (room) from the Chinese Medical Association Nephrology Branch (Trial Version 1). Chin J Nephrol 36:82-84.

7. State Council of People's Republic of China. Regulations on the management of medical waste. http://www.gov.cn/banshi/2005-08/02/content_19238.htm

8. National Environmental Protection Administration \& National Administration of Quality Supervision, Inspection and Quarantine. Standards for the discharge of waters in medical institutions. China Environment Press. 2006;GB184662005.

\title{
Rapid nosocomial spread of SARS-CoV-2 in a French geriatric unit
}

\author{
Philippe Vanhems MD, $\mathrm{PhD}^{1,2}$ (1), Mitra Saadatian-Elahi $\mathrm{PhD}^{1,2}$, Michel Chuzeville MD ${ }^{3}$, Elodie Marion $\mathrm{MD}^{1}$, \\ Louise Favrelle PharmD ${ }^{1}$, Delphine Hilliquin PharmD ${ }^{1}$, Geraldine Martin-Gaujard MD³ , Robin Gourmelon MD \\ Mathilde Noaillon MD $^{3}$, Nagham Khanafer PharmD, $\mathrm{PhD}^{1,2}$ and on behalf of COVID-Outcomes-HCL Consortium ${ }^{\mathrm{a}}$ \\ ${ }^{1}$ Service d'Hygiène, Epidémiologie et Prévention, Hôpital Edouard Herriot, Hospices Civils de Lyon, Lyon, France, ${ }^{2}$ Laboratoire des Pathogènes Emergents - \\ Fondation Mérieux, Centre International de Recherche en Infectiologie, Institut National de la Santé et de la Recherche Médicale U1111, Centre National de la \\ Recherche Scientifique, UMR5308, Ecole Normale Supérieure de Lyon, Université Claude Bernard Lyon 1, 21, Avenue Tony Garnier, 69007 Lyon, France and \\ ${ }^{3}$ Service de Gériatrie, Hôpital Edouard Herriot, Hospices Civils de Lyon, Lyon, France
}

To the Editor-SARS-CoV2 nosocomial transmission has been reported among healthcare professionals and patients. ${ }^{1}$ However, few studies have focused on nosocomial clusters in elderly patients at high risk of morbidity and mortality. ${ }^{1}$

With $>6,600$ cases, France is the fourth most affected European country. Edouard Herriot University Hospital (1,100 beds) is the largest emergency hospital in the Lyon area. We report the extremely rapid spread of COVID-19 in a 24-bed geriatric unit.

Epidemiological investigation revealed the existence of 2 potential index cases. The first was a 97-year-old male admitted to the emergency room (ER) with fever and dyspnea on February 29. The nasal swab for influenza and respiratory syncytial virus collected the same day was negative by polymerase chain reaction assay (PCR). The patient was transferred to the geriatric ward without complementary precautions. A second nasal swab was collected on March 7 and was positive for SARS-CoV2 by reverse-transcriptase PCR (RT-PCR). The second potential index case was a 76-year-old man admitted to the ER with cough and fever on February 1. Infection control measures were set up and nasal swab for influenza and respiratory syncytial virus (RSV) was negative by PCR. On March 3, the patient was transferred to the geriatric ward, where preventive air and contact measures were in place. The nasal swab previously collected was retested on March 6 and confirmed positive for SARS-CoV2 by RT-PCR.

Author for correspondence: Philippe Vanhems, E-mail: philippe.vanhems@chu-lyon.fr ${ }^{a}$ COVID-Outcomes-HCL Consortium (Edouard Herriot Hospital - Geriatric group, in alphabetic order): Adrait A, Benoist F, Castel-Kremer E, Chuzeville M, Dupin AC, Doh S, Escuret V, Favrelle L, Gourmelon R, Hilliquin D, Kim BA, Khanafer N, Marion E, Martin-Gaujard G, Moyenin Y, Noaillon M, Paulet-Lafuma H, Ricanet A, Vanhems P.

Cite this article: Vanhems $\mathrm{P}$, et al. (2020). Rapid nosocomial spread of SARS-CoV-2 in a French geriatric unit. Infection Control \& Hospital Epidemiology, 41: 866-867, https:// doi.org/10.1017/ice.2020.99
The first secondary case of COVID-19 was diagnosed on March 10, and 5 other cases (including a medical doctor) occurred in the same unit until March 13 (Fig. 1). Strict infection control measures and close monitoring of suspected cases of patients and healthcare professionals were subsequently performed to contain the intraunit transmission of the SARS-Cov-2 virus. The infection rate among patients was $20 \%$. Two patients (28.6\%) died on March 14. No additional cases occurred.

The likelihood of other sources of infection remains low, and no cases occurred in other areas of the ward. The area where the cases occurred was not primarily selected for COVID-19 hospitalizations, and only 123 cases had been reported to the Lyon Regional Health Agency as of March 14, for a metropolitan area of 2,300,000 inhabitants.

The rapid spread of nosocomial COVID-19 in this ward confirms the contagiousness of SARS-CoV-2 in healthcare settings and the high mortality rates in this population. The existence of super-shedders has been suggested, ${ }^{2,3}$ which could facilitate cluster emergence.

We wish to stress the urgency of strict application of COVID-19 infection control guidelines in healthcare facilities, particularly in geriatric units.

\section{References}

1. Wang J, Zhou M, Liu F. Exploring the reasons for healthcare workers infected with novel coronavirus disease 2019 (COVID-19) in China. J Hosp Infect 2020. pii: S0195-6701(20)30101-8. doi: 10.1016/j.jhin.2020.03.002.

2. Liu Y, Eggo RM, Kucharski AJ. Secondary attack rate and superspreading events for SARS-CoV-2. Lancet 2020;395(10227):e47. doi: 10.1016/S01406736(20)30462-1.

3. Riou J, Althaus CL. Pattern of early human-to-human transmission of Wuhan 2019 novel coronavirus (2019-nCoV), December 2019 to January 2020. Euro Surveill 2020;25:2000058.

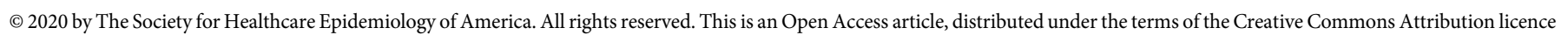
(http://creativecommons.org/licenses/by/4.0/), which permits unrestricted re-use, distribution, and reproduction in any medium, provided the original work is properly cited. 